\title{
PERANCANGAN KEMASAN PRODUK BERSTANDARISASI NASIONAL DI UMKM
} TEMPE

\author{
Nabila Yudisha1, Indra Gunawan², Rahmad Rezeki ${ }^{3}$, Rizkha Rida $^{4}$, Fiza Lubis ${ }^{5}$ \\ 1,2,3,4,5 Teknik Industri, Fakultas Teknik, Universitas Al-Azhar, J1. Pintu Air IV No.214, Kwala Bekala, \\ Kec. Medan Johor, Kota Medan, Sumatera Utara 20143 \\ *nabilayudisha@gmail.com
}

\begin{abstract}
ABSTRAK. Usaha Kecil Menengah (UMKM) di Desa Rengas Pulau mengalami kendala pada saat bermitra dengan perusahaan yang akan memasok produk tempe miliknya. Adapun penyebab dari kendala tersebut adalah masalah pengemasan produk yang belum terstandarisasi nasional, yaitu belum terdaftar BPOM, belum memiliki hak paten, dan kemasan yang kurang menarik perhatian konsumen. Oleh karena itu, peneliti melakukan pengabdian masyarakat pada UMKM tersebut untuk memperbaiki sekaligus meningkatkan kualitas kemasan produk dengan memberikan pelatihan terkait hal tersebut. Untuk perbaikan berkelanjutan, peneliti menyarankan pemilik UMKM untuk memasarkan produknya via Online melalui media sosial terkini. Ini merupakan salah satu langkah untuk mencapai usaha yang mengadaptasi Industri 4.0.
\end{abstract}

Kata kunci: Perancangan Kemasan; UMKM Tempe; Rekayasa Kualitas

ABSTRACT. Small and Medium Enterprises (MSMEs) in Rengas Pulau Village encountered problems when partnering with companies that would supply their tempeh products. The causes of these obstacles are product packaging problems that have not been nationally standardized, namely not yet registered with BPOM, not having patent rights, and packaging that does not attract the attention of consumers. Therefore, researchers carry out community service to these SMEs to improve and improve the quality of product packaging by providing training related to this. For continuous improvement, the researcher advises MSME owners to market their products online via the latest social media. This is one of the steps to achieve a business that adapts Industry 4.0.

Keywords: Packaging Design; Fermented Soybean Business; Quality Engineering

Terima 2 Januari 2022 Terima dan di revisi 3 Januari 2022 Disetujui 10 Januari 2022

\section{PENDAHULUAN}

Usaha Mikro, Kecil Menengah (UMKM) mempunyai peranan penting dalam pertumbuhan ekonomi dan industri suatu negara (Kurnia, Choudrie, 27 Mahbubur, \& Alzougool, 2015). Pemafaatan teknologi informasi dilakukan oleh UMKM umumnya diawali dari proses pemasaran. Menurut hasil penelitian yang dilakukan oleh Kurnia, dkk. (2015) bahwa sektor usaha kecil (UMKM) memanfaatkan teknologi pada proses pemasarannya untuk memperluas pangsa pasar atas produk yang dijual (Anggraini, 2008; Ayu Puti, 2013; Lestari, 2015; Reza, 2016; Triyaningsih, 2012). Memberikan label pada kemasan akan memudahkan konsumen dipasaran untuk mengingat produk yang kita jual.
Indonesia merupakan negara produsen tempe terbesar di dunia dan menjadi pasar kedelai terbesar di Asia. Sebanyak 50\% dari konsumsi kedelai Indonesia digunakan dalam bentuk tempe, $40 \%$ tahu, dan $10 \%$ dalam bentuk produk lain (seperti tauco, kecap, dan lainlain). Konsumsi tempe rata-rata per orang per tahun di Indonesia saat ini mencapai sekitar 6,45 kg (Astawan M, 2003).

Pada umumnya produksi tempe berujung pada hilir atau kegiatan pemasaran. Tahapan ini merupakan kunci dari keberhasilan suatu usaha. Pembuatan dan pengemasan produk harus dilakukan dengan menarik agar dapat dibeli oleh para distributor. Pengemasan sendiri memiliki arti ilmu, seni, dan teknologi membungkus atau melindungi produk untuk didistribusikan, disimpan, dijual, dan digunakan. Pengemasan juga mencakup pada proses merancang, mengevaluasi, dan memproduksi produk. Pengemasan dapat 
digambarkan sebagai suatu sistem terkoordinasi dalam mempersiapkan barang untuk, pergudangan, transportasi, penjualan, logistik, dan penggunaan akhir.

Fungsi dari pengemasan antara lain, mengawetkan, melindungi, mengangkut, menginformasikan, dan menjual (Soroka, 2002). Diharapkan dengan adanya kegiatan pengabdian masyarakat dapat memajukan dan meningkatkan penjualan dan perekonomian Usaha Kecil pembuatan tempe yang berada di Desa Rengas Pulau. Masalah utama yang sering dihadapi oleh UKM adalah pada bidang pemasaran. Kegiatan pemasaran yang di maksud untuk memperbaiki kemasan produk yang belum terstandarisasi secara nasional. Adapun standar desain dalam pengemasan produk menurut BSN antara lain nama produk dan logo, keterangan komposisi dan bahan tambahan, keterangan tanggal kedaluarsa, logo halal atau SNI, dan kemasan yang tidak mudah rusak (Direktorat Jenderal Industri Kecil, 2010)

Berdasarkan hasil pengamatan yang dilakukan oleh tim pengabdian masyarakat terhadap pabrik tempe industri rumah tangga desa Rengas Pulau maka diperoleh beberapa masalah yang dihadapi yaitu:

1. Mitra pengabdian masyarakat mengalami permasalahan pada perijinan pembuatan label nomor BPOM.

2. Mitra pengabdian masyarakat mengalami permasalahan pada perijinan hak paten nama produk.

3. Mitra pengabdian masyarakat mengalami permasalahan pada kemasan produk dan label produk yang kurang menarik perhatian konsumen.

Berdasarkan beberapa permasalahan yang ada, tim pengabdian masyarakat memberikan fokus utama terhadap kegiatan ini adalah pentingnya label suatu produk terhadap daya saing usaha.

\section{METODE}

Kegiatan Pengabdian Kepada Masyarakat yang dilakukan di Desa Rengas Pulau adalah mendampingi pelaku usaha UMKM tempe dalam menyusun laporan keuangan dan strategi pemasaran. Adapun metode pelaksanaan pemecahan masalah dalam pengabdian ini disajikan dalam Tabel 1 berikut ini:

Tabel 1. Metode Pendekatan dan Pemecahan Masalah

\begin{tabular}{|c|c|c|}
\hline \multicolumn{2}{|c|}{ Uraian } & \multirow{2}{*}{$\begin{array}{c}\text { Metode } \\
\text { Pelaksanaan dan } \\
\text { Pemecahan } \\
\text { Masalah }\end{array}$} \\
\hline Masalah & Solusi & \\
\hline $\begin{array}{l}\text { Belum ada } \\
\text { izin BPOM }\end{array}$ & $\begin{array}{l}\text { Diberikan } \\
\text { pendampingan } \\
\text { dalam } \\
\text { pembuatan } \\
\text { izin BPOM }\end{array}$ & $\begin{array}{l}\text { Diberikan pelatihan } \\
\text { dan pendampingan } \\
\text { Langkah-langkah } \\
\text { dalam pembuatan } \\
\text { izin BPOM }\end{array}$ \\
\hline $\begin{array}{l}\text { Belum Ada } \\
\text { Hak Paten }\end{array}$ & $\begin{array}{l}\text { Diberikan } \\
\text { pendampingan } \\
\text { dalam } \\
\text { pembuatan } \\
\text { Hak Paten }\end{array}$ & $\begin{array}{l}\text { Diberikan pelatihan } \\
\text { dan pendampingan } \\
\text { Langkah-langkah } \\
\text { dalam pembuatan } \\
\text { Hak Paten }\end{array}$ \\
\hline $\begin{array}{l}\text { Belum } \\
\text { adanya } \\
\text { pengemasan } \\
\text { produk dan } \\
\text { pelabelan }\end{array}$ & $\begin{array}{l}\text { Diberikan } \\
\text { pelatihan dan } \\
\text { pendampingan } \\
\text { pembuatan } \\
\text { kemasan dan } \\
\text { pelabelan }\end{array}$ & $\begin{array}{l}\text { Dibuatkan format } \\
\text { pengemasan yang } \\
\text { aman dan higienis } \\
\text { serta praktis dan } \\
\text { pelabelan yang } \\
\text { menarik dan mudah } \\
\text { dikenal konsumen }\end{array}$ \\
\hline \multicolumn{3}{|c|}{$\begin{array}{l}\text { Pelaksanan pengabdian merancang kegiatan } \\
\text { sesuai dengan masalah yang muncul dan } \\
\text { dampak negatif dari masalah tersebut. Metode } \\
\text { yang akan dilaksanakan untuk memecahkan } \\
\text { masalah disajikan pada Tabel } 1 .\end{array}$} \\
\hline
\end{tabular}

\section{HASIL DAN PEMBAHASAN}

Kegiatan pengabdian masyarakat dilaksanakan pada usaha kecil pembuatan tempe UMKM tempe yang berlokasi di Desa Rengas Pulau, Medan. Tim pengabdian terdiri dari ketua dan anggota yang ikut terlibat pada kegiatan Pengabdian Masyarakat. Pada tanggal 7 Agustus 2021 bertempat di Rumah pak suratman pemilik UMKM Tempe dilaksanakan Focus Grup Discussion (FGD). Berdasarkan hasil Forum Grup Discussion ditetapkan beberapa permasalahan yang menjadi fokus pelaksanaan pada kegiatan pengabdian masyarakat ini, yaitu:

1. Permasalahan pada perijinan pembuatan label nomor BPOM.

2. Permasalahan pada perijinan hak paten nama produk.

3. Permasalahan pada kemasan produk dan label produk yang kurang menarik perhatian konsumen.

Beberapa hasil kegiatan yang telah dilakukan oleh Tim Pengabdian Masyarakat bersama mitra usaha sebagai berikut: 
1. Pemberian pengarahan dalam pembuatan BPOM dan Hak Paten nama produk, apa saja yang harus di siapkan dan langkahlangkah pengurusannya.

2. Pembuatan desain banner dan label merek produk.

Pada kegiatan ini dilakukan secara bersama antara tim pengabdian masyarakat dengan mitra usaha dalam hal ini pengusaha tempe, yang mana dalam pelaksanaan kegiatan dilakukan melalui forum komunikasi 2 (dua) arah sehingga akan terjadi hubungan timbal balik pada kedua belah pihak.

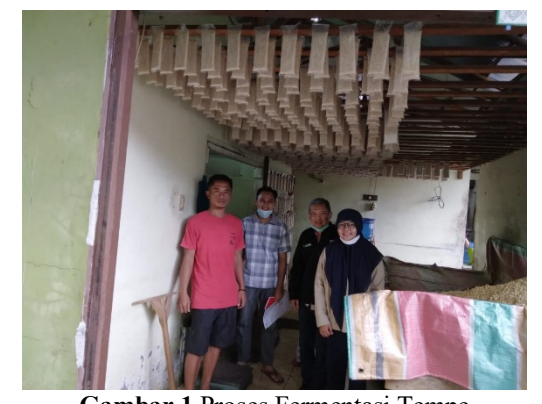

Gambar 1.Proses Fermentasi Tempe

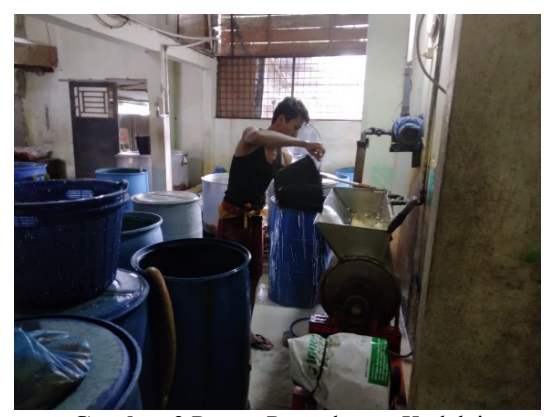

Gambar 2.Proses Perendaman Kedelai

\section{SIMPULAN}

Pelaksanaan kegiatan pengabdian masyarakat yang berjudul sosialisasi Perbaikan proses pengemasan tempe di industri rumah tangga desan rengas pulau. melalui program kegiatan pembuatan kemasan dan label kemasan, dan menyosialisasikan langkah dalam pengurusan BPOM dan Hak Paten. Kemasan yang menarik dan memiliki nama produk akan lebih mudah konsumen untuk tetap membeli produk kita.

\section{UCAPAN TERIMA KASIH}

Dengan selesaikan pengabdian terhadap masyarakat ini di ucapkan banyak terima kasih Kepada UMKM tempe yang berlokasi di Desa Rengas Pulau, Medan.

\section{DAFTAR PUSTAKA}

Anggraini, A. A. 2008. Manajemen Keyword: Strategi Pemasaran Online Menggunakan Search Engine. Jurnal Pendidikan Akuntansi Indonesia, 6(2). (https://doi.org/https://doi.org/10.21831/jp ai.v6 i2.934)

Astawan, M. 2003. Tempe: Cegah Penuaan \& Kanker Payudara. Kompas

Ayu Puti, E. 2013. Aplikasi Instagram Sebagai Media Komunikasi Pemasaran Online Shop (Studi Deskriptif Kualitatif Aplikasi Instagarm Sebagai Media Komunikasi Pemasaran Online Shop). Surabaya: FISIP Universitas Pembangunan Nasional "Veteran" Jawa Timur

Direktorat Jenderal Industri Kecil. 2010. Kemasan Fleksibel. Jakarta: Departemen Perindustrian

Soroka. 2002. Fundamentals of Packaging Technology, Institute of Packaging Professionals 